\title{
Landmark guided erector spinae plane block as a part of multimodal analgesia in thoracolumbar spine surgeries
}

Citation: Goel VK, Vadera HK, Mistry T. Landmark guided erector spinae plane block as a part of multimodal analgesia in thoracolumbar spine surgeries. Anaesth pain \& intensive care 2019;23(4):404-405. DOI: 10.35975/apic.v23i4.1180

\section{Dear Editor,}

Conventionally, ultrasound guided erector spinae plane block (ESB) has been used for postoperative pain management in lumbosacral spine surgeries. ${ }^{[1]}$ We want to share our experience with landmark guided erector spinae plane block (LESB) in this set of surgeries.

We have performed LESB as described by Vadera et al. ${ }^{[2]}$ in four ASA status 1, male patients aged 25 to $40 \mathrm{y}$, scheduled for surgical decompression and instrumentation (Table 1). Written informed consent was obtained from all patients during pre-anesthesia check-up. LESB was performed in prone position except in second patient in which it was done in lateral decubitus. The block was performed before or after induction, intraoperatively after the closure of muscle layer with the help of surgeon and after completion of surgery but before extubation. Inj ropivacaine $0.2 \% 20 \mathrm{ml}$ was injected on each side after negative aspiration for blood or air. All patients received standard general anesthesia and there were no significant intraoperative hemodynamic changes or any other adverse events. Intraoperatively, each patient received $1 \mathrm{gm}$ paracetamol, $8 \mathrm{mg}$ dexamethasone and $30 \mathrm{mg}$ ketorolac intravenously as a part of multimodal analgesia. After skin closure, patients were extubated and shifted to post anesthesia care unit (PACU) for observation. Pain score was recorded using numeric rating scale (NRS). In PACU, our patients received paracetamol 1 gm 6 hourly, ketorolac $30 \mathrm{mg} 8$ hourly, and pregabalin $75 \mathrm{mg}$ at night as per hospital protocol. Intravenous fentanyl $0.5-1 \mu \mathrm{g} / \mathrm{kg}$ was used as rescue analgesic if required. All four patients reported NRS score $\leq 5$ at rest in first $24 \mathrm{~h}$ (Table 1) and two patients required rescue analgesia after $18 \mathrm{~h}$ following surgery.

The postoperative pain is a nightmare for the patients after spine surgeries especially after instrumentation and fusion surgeries. So, adequate pain relief helps in early mobilization and decrease in morbidity and hospital stay. Ultrasound guided ESB has shown to reduce postoperative opioid requirement and improves patient satisfaction in lumbar spine surgery patients. ${ }^{3}$ But unfortunately not all anesthesiologists have access to ultrasound machines in the operating rooms. LESB is a simple technique which can be used to provide effective and reliable analgesia in absence of ultrasound. Further investigations and randomized controlled trials are required.

\section{Declaration of patient consent:}

Appropriate patient consent was obtained from all patients to be reported in the journal.

Table 1: Postoperative pain score and opioid consumption:

\begin{tabular}{|c|c|c|c|c|c|c|c|c|c|}
\hline \multirow{2}{*}{ Pt } & \multirow{2}{*}{ Surgery } & \multirow{2}{*}{$\begin{array}{l}\text { Time of } \\
\text { ESPB }\end{array}$} & \multirow{2}{*}{$\begin{array}{l}\text { Duration of } \\
\text { surgery (min) }\end{array}$} & \multicolumn{5}{|c|}{ Numeric Rating Scale } & \multirow{2}{*}{$\begin{array}{c}\text { Fentanyl } \\
\text { Consumption }\end{array}$} \\
\hline & & & & $\begin{array}{c}\text { Post } \\
\text { Extubation }\end{array}$ & $6 \mathrm{~h}$ & 12 & 18 & 24 & \\
\hline 1 & $\begin{array}{l}\text { T8-T9 spondylodiscitis- } \\
\text { Instrumented stabilization and } \\
\text { decompression }\end{array}$ & $\begin{array}{l}P \text { o s t - } \\
\text { induction }\end{array}$ & 130 & 0 & 1 & 2 & 3 & 4 & Nil \\
\hline 2 & L4-L5 decompression & Pre-induction & 90 & 0 & 1 & 2 & 3 & 4 & Nil \\
\hline 3 & $\begin{array}{l}\text { T12 burst fracture with normal neurology } \\
\text { - decompression and instrumented } \\
\text { stabilization }\end{array}$ & $\begin{array}{l}\text { Before skin } \\
\text { closure }\end{array}$ & 120 & 0 & 1 & 2 & 3 & 4 & $20 \mathrm{mcg}$ \\
\hline 4 & $\begin{array}{l}\text { T10-T12 Instrumented stabilization and } \\
\text { decompression }\end{array}$ & Post- surgery & 150 & 0 & 1 & 3 & 3 & 5 & $30 \mathrm{mcg}$ \\
\hline
\end{tabular}


Conflicts of interest: There is no conflict of interest.

Vipin Kumar Goel ${ }^{1}$, Hetal Kumar Vadera ${ }^{2}$, Tuhin Mistry $^{3}$

${ }^{1}$ Consultant, Department of Anaesthesiology, Ganga Medical Centre Hospitals Pvt Ltd, Coimbatore, (India) ${ }^{2}$ Consultant Anaesthesiologist, Sterling
Hospital, Rajkot, Gujarat, (India) 35enior Resident, Onco Anaesthesiology Pain and Palliative Care, Dr B. R. Ambedkar Institute Rotary Cancer Hospital, All India Institute of Medical Sciences, New Delhi, (India)

Correspondence: Dr Tuhin Mistry dr.tuhin2014@gmail. com; Mobile: 918240823526

\title{
REFERENCES
}

1. Melvin JP, Schrot RJ, Chu GM, Chin KJ. Low thoracic erector spinae plane block for perioperative analgesia in lumbosacral spine surgery: a case series. Can $J$ Anaesth. 2018;65(9):1057-65. [PubMed] DOI: 10.1007/s12630-018-1145-8.

2. Vadera HK, Mistry T. Erector spinae plane block: Anatomical landmarkguided technique. Saudi J Anaesth 2019;13:268-9 [PubMed] [Free Full Text] D0I:10.4103/sja.SJA $780 \quad 18$
3. Tsui BCH, Fonseca A, Munshey F, McFadyen G, Caruso TJ. The erector spinae plane (ESP) block: A pooled review of 242 cases. J Clin Anesth. 2018;53:29-34. [PubMed] DOI: 10.1016/j.jclinane.2018.09.036

\section{An alternative approach for continuous monitoring of heart and breath sounds in pediatric patients}

\begin{abstract}
Citation: Kumar D, Ali S, Khan FA, Suleman M. An alternative approach for continuous monitoring of heart and breath sounds in
\end{abstract} pediatric patients. Anaesth pain \& intensive care 2019;23(4):405-406. DOI: 10.35975/apic.v23i4.1180

Anesthetic management in neonates, infants and young children is always a challenge. Both esophageal and precordial stethoscopes are used for continuous monitoring of heart and breath sounds in this age group. ${ }^{1}$ Recent (2018) publication of Standards for Safe Practice of Anesthesia by World Health Organization-World Federation of Societies of Anesthesiologists (WHO-WFSA) have also recommended monitoring with a precordial or esophageal stethoscope. ${ }^{2}$ By using an esophageal stethoscope both heart and breath sounds can be continuously monitored and any obstruction of endotracheal tube (ETT) can be readily detected. However, the detection of one lung ventilation due to incidental endobronchial ETT placement during surgical positioning and tissue handling may be difficult. Complications of esophageal stethoscope placement have been reported e.g. incidental tracheal and bronchial insertion resulting in hypoxia, hoarseness, oropharyngeal trauma or bleeding. ${ }^{3}$

Precordial stethoscope on the other hand is a relatively safe, non-invasive and inexpensive alternative to esophageal stethoscope. It is usually fixed on the chest wall to the left of lower part of sternum in order to auscultate both the heart and breath sounds. However, it's applicability is limited since it is easily displaced and its contact with the skin may require frequent refixing during surgery interfering with sterility. The current practice for the fixation of precordial stethoscope varies among anesthesiologists as there is no standard recommendation.

We have used Self Adhesive Fabric Tape (Mefix) in our

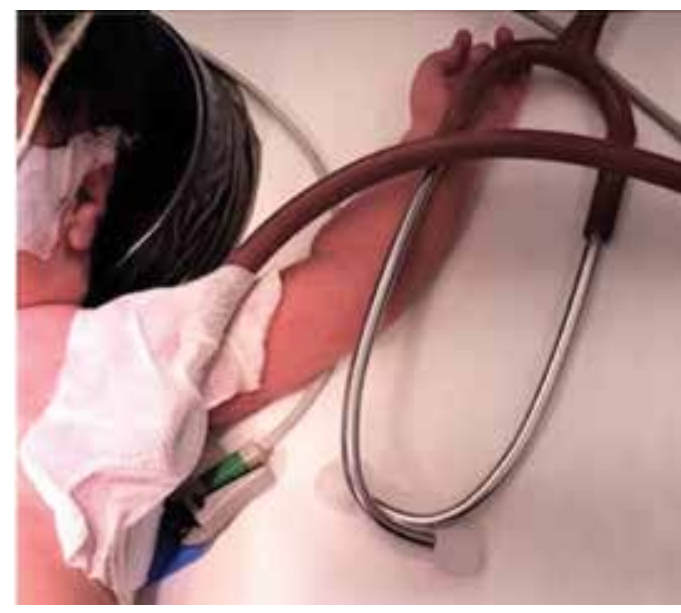

Figure-I: Shows stethoscope and Mefix $10 \times 10$ fixed in $5^{\text {th }}$ intercostal space for lower abdominal surgery and in the left axilla for contralateral thoracic surgery. 